\title{
METHODOLOGICAL DEVELOPMENTS IN 3D SCANNING AND MODELLING OF ARCHAEOLOGICAL FRENCH HERITAGE SITE : THE BRONZE AGE PAINTED CAVE OF « LES FRAUX », DORDOGNE (FRANCE)
}

Tribute to Edmond Goineaud, owner of the cave « Les Fraux $(\dagger)$

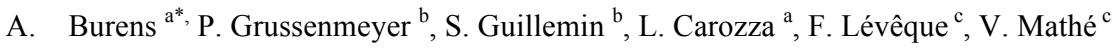

\author{
${ }^{a}$ Environmental Geography Laboratory - UMR 5602 GEODE, 31058 Toulouse, France - \\ (albane.burens, laurent.carozza)@univ-tlse2.fr \\ b Icube Laboratory, UMR 7357, Photogrammetry and Geomatics Group, INSA de Strasbourg, 67084 Strasboug, \\ France - (pierre.grussenmeyer, samuel.guillemin) @insa-strasbourg.fr \\ c UMR 7266 LIENSs, Université de La Rochelle, La Rochelle, France - (fleveque, vmathe)@univ-lr.fr
}

\section{Special Session: Documentation of World Heritage Sites}

KEY WORDS: Cultural Heritage, painted cave, TLS, Photogrammetry, Close Range, 3D Modelling, documentation, PDF-3D

\begin{abstract}
:
For six years, an interdisciplinary team of archaeologists, surveyors, environmentalists and archaeometrists have jointly carried out the study of a Bronze Age painted cave, registrered in the French Historical Monuments. The archaeological cave of Les Fraux (Saint-Martin-de-Fressengeas, Dordogne) forms a wide network of galleries, characterized by the exceptional richness of its archaeological remains such as ceramic and metal deposits, parietal representation and about domestic fireplaces. This cave is the only protohistorical site in Europe wherein are gathered testimonies of domestic, spiritual and artistic activities. Fortunately, the cave was closed at the end of the Bronze Age, following to the collapse of its entrance. The site was re-discovered in 1989 and its study started in 2007. The study in progress takes place in a new kind of tool founded by the CNRS's Institute of Ecology and Environment. The purpose of this observatory is the promotion of new methodologies and experimental studies in Global Ecology. In that framework, 3D models of the cave constitute the common work support and the best way for scientific communication for the various studies conducted on the site by nearly forty researchers. In this specific context, a partnership among archaeologists and surveyors from INSA Strasbourg allows the team to develop, in an interdisciplinary way, new methods of data acquiring based on contact-free measurements techniques in order to acquire a full 3D-documentation. This work is conducted in compliance with the integrity of the site. Different techniques based on Terrestrial Laser Scanning, Digital Photogrammetry and Spatial Imaging System have been used in order to generate a geometric and photorealistic 3D model from the combination of point clouds and photogrammetric images, for both visualization and accurate documentation purposes. Various scales of acquiring and diverse resolutions have been applied according to the subject: global volume cave, parietal representations, deposits... The aim of this paper is to issue a statement of the different $3 \mathrm{D}$ technologies tested in this outstanding site and the integration of magnetic measurements in the models.
\end{abstract}

\section{INTRODUCTION}

This paper deals with 3D reconstruction and visualization of the exceptional heritage site « les Fraux » in which new methods of data acquiring based on contact-free measurements techniques have been improved in order to acquire a full 3D-documentation without damaging this underground anthropic network, registered in the French Historical Monuments. The purpose is to present experiences and a selection of results gained during the recording of the cave. In this study we propose to explain the recording methodology applied on this site for six years, as part of a interdisciplinary and multiscale approach. Besides, main methodological key issues faced will be exposed.

\section{ARCHAEOLOGICAL AND SCIENTIFIC CONTEXT}

The Bronze Age cave "Les Fraux", located at Saint-Martin-deFressengeas (Dordogne, France), is the only protohistorical site in Europe wherein are gathered testimonies of domestic, symbolic and artistic activities (schematics and geometrics lines drawn in the clay covering the walls). The site has been settled during nearly 3 centuries (from the middle to the final Bronze
Age: 1450-1150 BC). The cave forms a wide underground network, of narrow horizontal galleries of more than $1 \mathrm{~km}$. It is characterized by the exceptional richness of its archaeological remains such as many ceramic and metal deposits, parietal representations (like engravings, fingerings incised in the clay walls, paintings...) and about sixty domestic fireplaces (Carozza et al., 2009). Fortunately, the cave was closed at the end of the Bronze Age, following to the collapse of its entrance which preserved unharmed the archaeological remains until today. After closure, the site was accidently re-discovered in 1989. Following its expertise, which highlighted its extraordinary archaeological and heritage interest, the cave was registrered in the French Historical Monuments in 1995.

Nowadays, the cave is not immune to a new collapse in the coming years according to the French Office of Geological and Mining Research (BRGM).

Since 2007, a multidisciplinary project coordinated by L. Carozza is bringing together different specialists for the surveying and recording, excavations, recording of parietal art, setup of magnetic field measurements...

The study in progress takes place in a new kind of tool founded by the CNRS' Institute of Ecology and Environment (A. Burens 
dir.). The purpose of this observatory is the promotion of new methodologies and experimental studies in Global Ecology and the analysis of interactions of Bronze Age societies with their environment. These interactions are studied by analyzing the alternating phases made of strong anthropic constraints and steps back to natural functioning. In that framework, 3D models of the cave constitute the common work support and the best way for scientific communication for the various studies conducted on the site by nearly forty researchers and students. In this peculiar context, a partnership among archaeologists and surveyors from INSA Strasbourg (P. Grussenmeyer, S. Guillemin) allows the team to develop, in an interdisciplinary way, new methods of data acquiring based on contact-free measurements techniques in order to acquire a full 3Ddocumentation for the whole structural elements of the cave and the archaeological remains (Grussenmeyer et al, 2010; Burens et al, 2011). This work is conducted in compliance with the integrity of the site which must be preserved in a heritage order: it is essential that archaeological soils, ceramic and metal deposits, fireplaces, engravings walls and fingerings remain intact in the cave. Neither remains should be handled or get out of the site: they have to be studied, registered, measured and drawn in situ, without any contact, or in the basis of 3D-models. Which is to say that this requirement has a very important impact on how to study the site and on the conditions of data acquiring. The difficulty is in working with non-invasive techniques like contact free measurement of ceramic deposits and parietal representations

\section{METHODOLOGY}

It comes to no surprise that nowadays main projects dedicated to the recording of archaeological caves combine terrestrial laser scanning and close range photogrammetry (Lerma et al, 2009; Gonzales-Aguilera et al., 2009). These techniques not only yield to drawings such as sections and elevations, but also to photo-realistic perspective views and visual navigation worlds in $3 \mathrm{D}$ environments.

Since 6 years, work in progress in the cave involves different techniques based on Terrestrial Laser Scanning, Digital Photogrammetry and Spatial Imaging System, in order to generate a geometric and photorealistic 3D model of the of the whole structural elements of the cave and archaeological main artefacts (Fig. 1). This model is determined by the combination of point clouds and photogrammetric images, for both visualization and accurate documentation purposes. It is conceived as a common research tool, usable by all partners of the scientific and multidisciplinary team. By the way, our approach is based on the complementarity of data which are produced by the different scales of $3 \mathrm{D}$ recording used in the cave : global volume cave, parietal representations, deposits... In this study we showed evidence that it is possible to merge together, in the same depiction system, several roots of informations as it it shown in the recent work conducted on magnetic field mapping. Furthermore, we wanted to test innovative and experimental approaches combining photogrammetry and terrestrial laser scanning, including for parietal works (photorealistic rendering).

\subsection{Overall 3D-recording of the cave's structural elements}

The overall recording of the cave by terrestrial laser scanning was our first goal since it ensures the georeferencing of any type of object, image or measurement and an accurate indexing compatibility of the data between the researchers involved in the project.

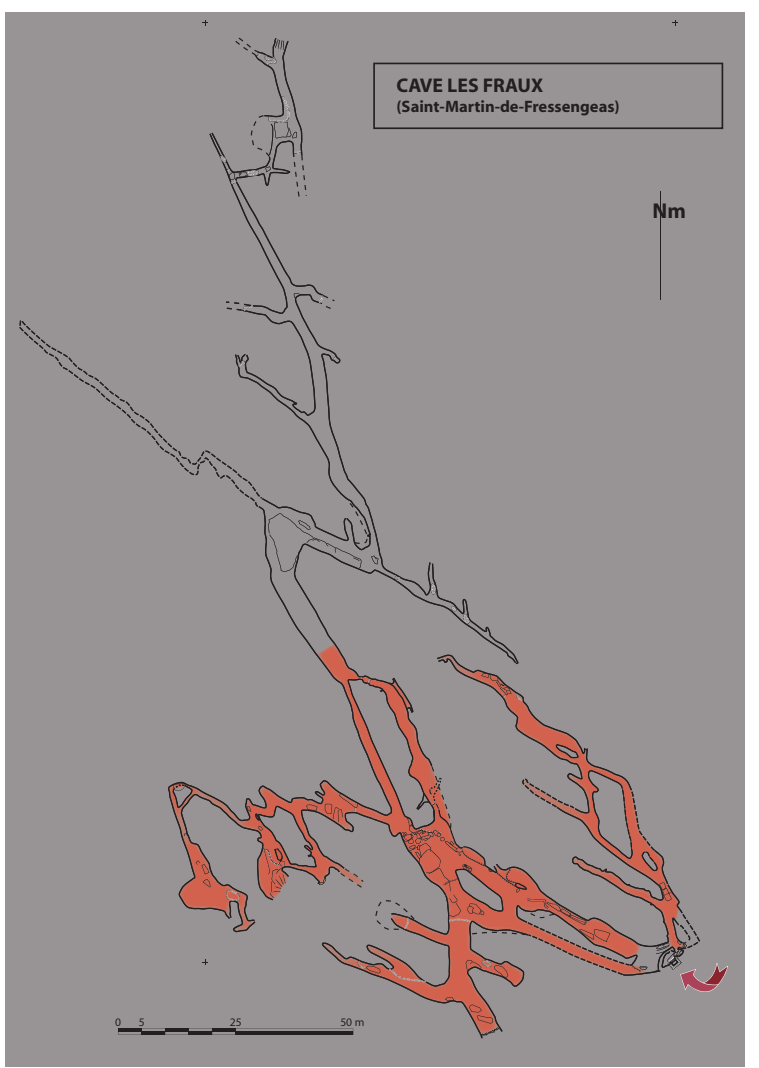

Figure 1. Map of the archaeological cave Les Fraux. The colourful galleries have been scanned from 2008 to 2013.

The study began with the consolidation of the topography network and the creation of polygonal traverses inside the cave thanks to a total station. This network is connected outside by several points measured by differential GPS. All the data was recorded in the French Geodetic Reference System (Lambert 2). First campaigns of recording were done with the scanner Photon 120 FARO, which well adapted in the middle underground passage. Since 2012, data acquisition has been performed using a FARO Focus 3D. The expected accuracy of both scanners is about $2 \mathrm{~mm}$ at $25 \mathrm{~m}$. Spheres and targets have been used for the registration of the point clouds and the geo-referencing (Fig. 3). The acquisition of point clouds occurs through repetition in space of scanning stations along the galleries. An overlapping area between two stations is routinely provided (for the details of the recording methodology by TLS, the reader can refer to Grussenmeyer et al, 2010a et b). One TLS station requires about $7 \mathrm{mn}$ for forty Million points. The distance between the stations varies between $2 \mathrm{~m}$ to $5 \mathrm{~m}$ depending on the complexity of the cave sections. More than $430 \mathrm{~m}$ of galleries have been recorded at this stage. This work required more than one hundred TLS stations and 24 days of recording in the cave. If we consider a point density of $1 \mathrm{pt} / \mathrm{mm}$, each meter provides approximately 10 Mo points. The post-processing work, the merging and georeferencing of the point clouds have been thoroughly processed by B. Cazalet, V. Léglise, E. Moisan (students from INSA Strasbourg under the supervision of Pierre Grussenmeyer). Handling data from multiple stations requires a resampling of the point clouds saved in ASCII format and afterwards merged into a uniform point cloud. Georeferencing of the individual point clouds avoid a time consuming consolidation step. The need to facilitate the exchange and dissemination of data within the team led us to export the global 3D model of the cave, resampled at $1 \mathrm{pt} / \mathrm{cm}$, in PDF 3D (Fig. 2). This format allows as well some measuring functions and 
toolkits (distances, sections, etc.) and visualization options such as wireframe, shaded, solid, vertices, etc. Incidentally, the team is actually working on the $3 \mathrm{D}$ recording of ceramic deposits placed along the galleries using FARO Focus 3D and its integrated camera (Fig. 3). Work in progress has revealed that the 3D-model thereby obtained and transformed in PDF 3D allows us to draw, measure and define the section and the typology of every ceramics without any contact. It is worthwhile at this stage to consider that this approach is not relevant for unattainable deposits (pottery almost entirely hidden in rocky chaos for instance) (Fig. 3). But that kind of contactless study prevents all technological analysis.

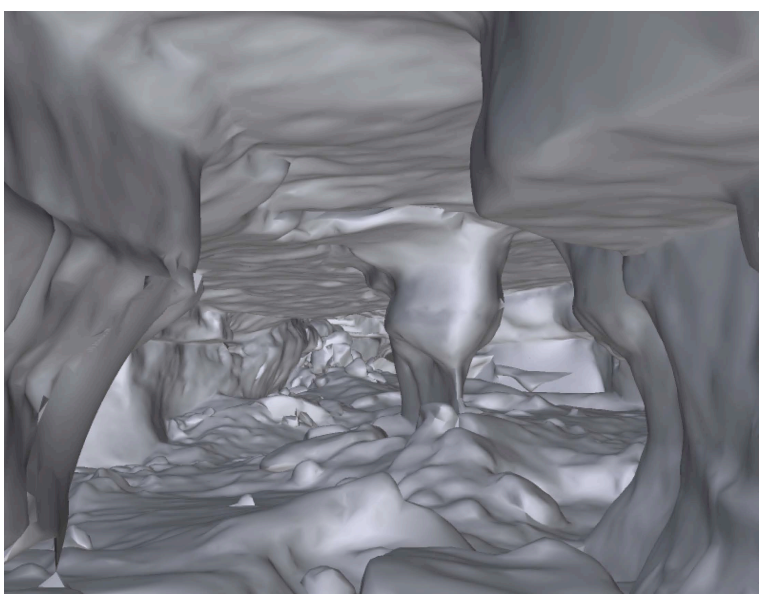

Figure 2. 3D model of the cave from the PDF-3D viewer.

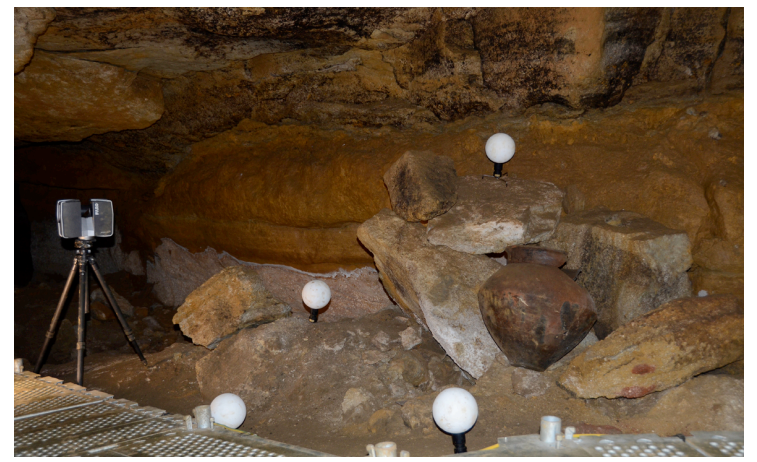

Figure 3. 3D-recording of a Bronze age ceramic deposit (using the Faro Focus 3D).

\subsection{D magnetic field mapping}

Among the various methodological developments conducted in « Les Fraux », the project « magnetic field mapping», which is managed by F. Lévêque (AIR program ; CPER University of La Rochelle), is particularly interesting in terms of 3D (Lévêque et al., 2010). Indeed, it succeeded to merge together, in the same depiction system, several roots of magnetic, topographic, archaeological information.

On outdoors archaeological sites, drawings of local distortions of the earth magnetic field (generated by thermal impact on sediment) allows researchers to try to locate ancient fireplaces (visible, or not). For the first time, F. Leveque and colleagues have adapted this technique of magnetic survey to underground network (fig. 4).

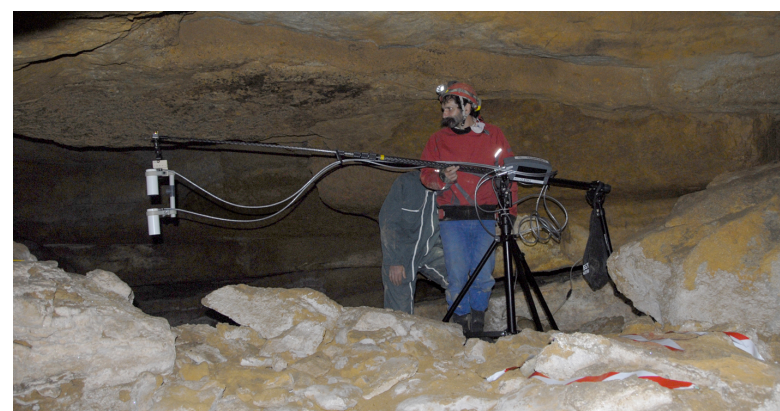

Figure 4. Measurements of magnetic field in the cave Les Fraux, using a dual sensor magnetometer fixed on a tripod (non invasive equipment).

The very complex topographic configuration of the underground places required a $3 \mathrm{D}$ acquisition protocol (instead of the usual planar acquisition protocol). As all rock are susceptive to deform the magnetic field, both magnetic and topographic information are merged in the same 3D-model of the cave in order to be able to distinguish topographic effects from fire impacts. Here, the variation of magnetic field intensity is represented by a colour scale, in a space divided in elementary volumes (voxels) (fig. 5). Measurements of magnetic field are recorded using a dual sensor magnetometer coupled to a prism $\left(360^{\circ}\right)(10$ measurements/s on-going). The whole equipment is hanged at the end of a telescopic boom pole fixed on a tripod (Fig. 4). Geo-location of measurements is ensured by tracking with a total station (TRIMBLE S8) following the prism.

\subsection{Photorealistic rendering}

In archaeological caves, parietal representations study requires the processing of very high definition images (El-Hakim et al., 2004; Fryer et al., 2005), in a more accurate scale from that used for the volume of the underground network. A common solution is the correlation between high resolution digital photographs of pannels and the 3D volumetric model of the cave.

The aim of the experimental work which is developed in « Les Fraux » since 2008 is to find an interface between the 3D imaging methods and the photographic and manual works of parietal art specialists. That method allows a better reading of superposition of the archaeological tracings (relative chronology), analysis of the section of tracings and nature of the impacts on the rock, as well as identification of tools by their stigmas. This is not a view shared by everyone, but what should be very useful for archaeologists should be the generalization of parietal representations' drawings using orthophotos based on the 3D-model (figure 6f).

In the cave Les Fraux, the team wanted to test the simultaneous acquisition of the $3 \mathrm{D}$ model coupled with the digital shots and automatically georeferenced by the Trimble VX equipped with an internal camera (unfortunately limited to 3,2 Mpixels).

The recording of point clouds with a Faro Photon 120 laser scanner equipped with a Nikon camera color kit was not either considered satisfactory since it was not possible to change the camera settings during the automated recording process of the images. As a result, we were unable to process automatically the produced photographs. 

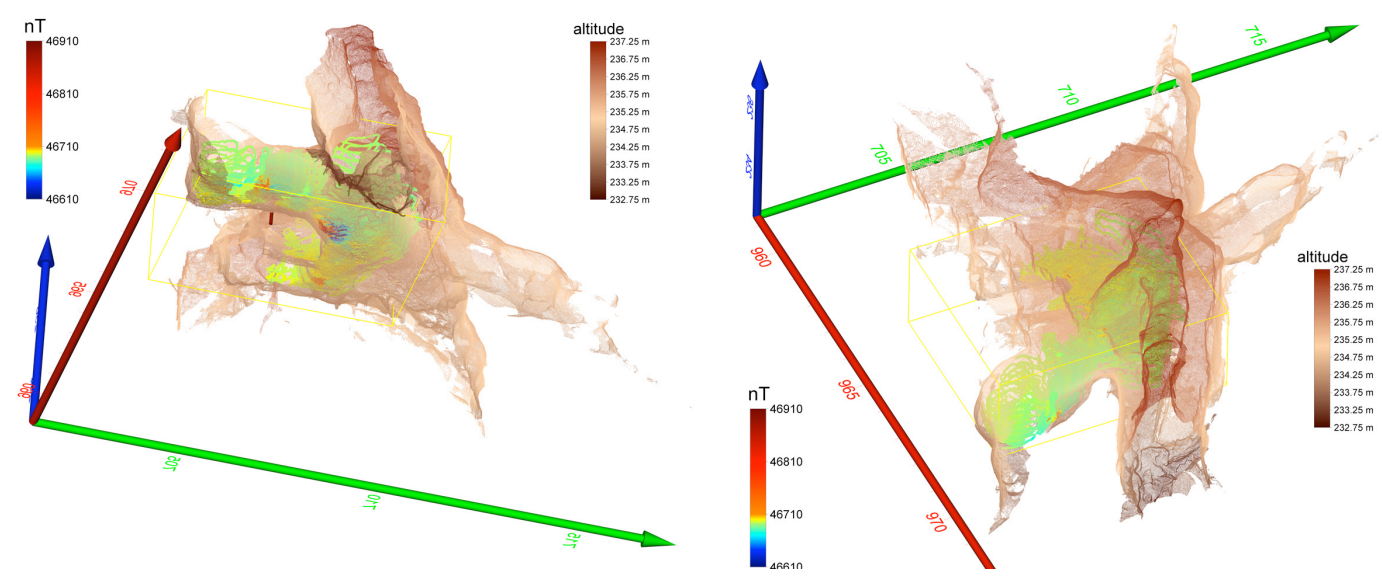

Figure 5. In the same 3D-depiction, merging of magnetic field intensity's point clouds with the topography of the surface cave's walls from the sector $29(1 \mathrm{pt} / \mathrm{cm})$.
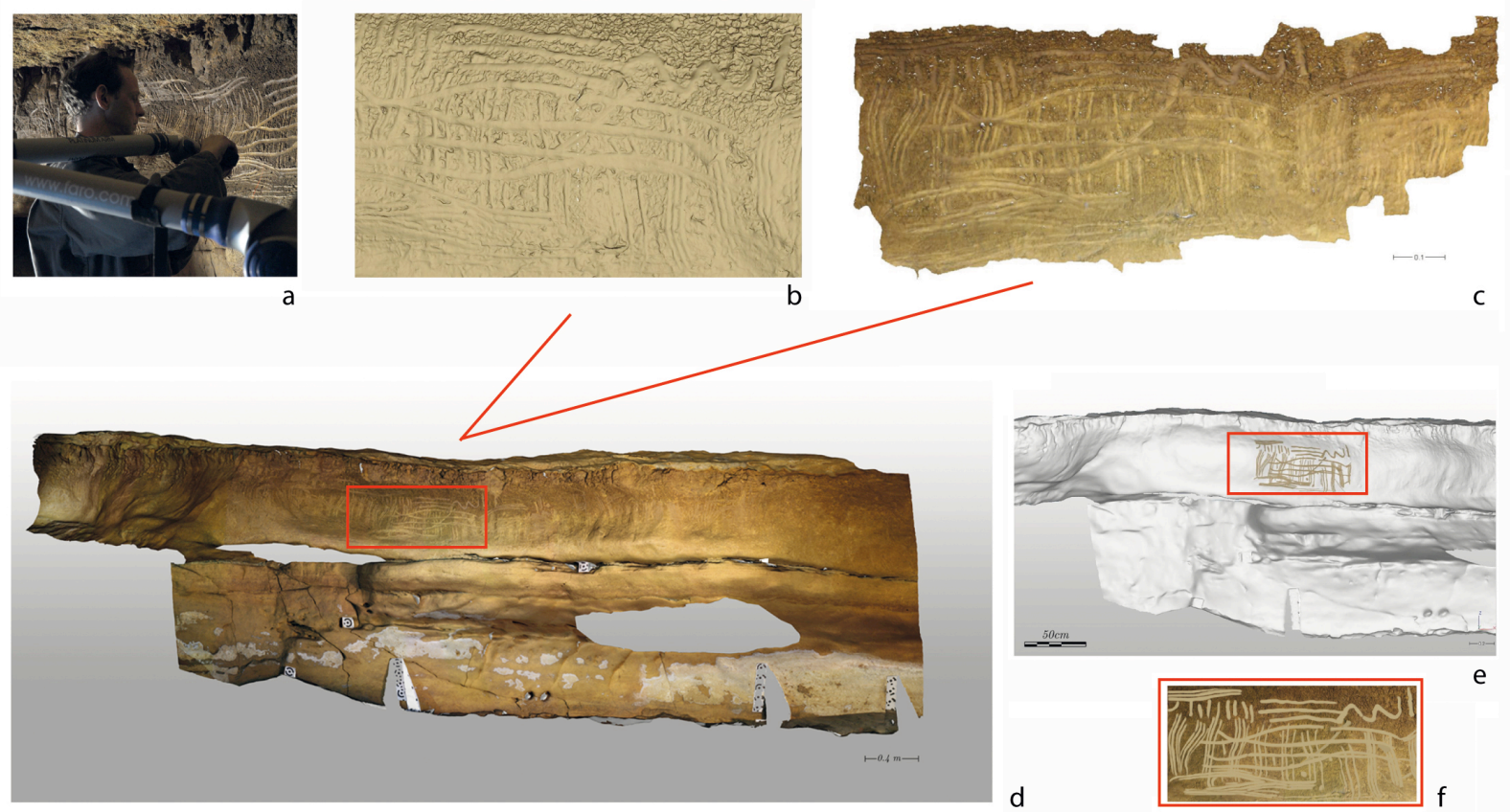

Figure 6. 3D-recording of Bronze age fingerings in the clay-wall of the main panel from the sector 13 of the cave. a: recording test with the Faro ScanArm; b: view of the high density point cloud recording using ScanArm ; c: digital surface of a selected piece of the pannel; d: textured 3D-model; e: projection of drawn fingerings on the 3D-model; f: detail of the digital drawing from the orthophoto extracted from the 3D-model.

In 2010, we took a series of very high resolution digital images of a large clay panel, using a Canon EOS 5D equipped with $85 \mathrm{~mm}$ and $20 \mathrm{~mm}$ lenses and mounted on a panoramic pan head, in order to realize accurate panoramas views with a pixel size in the object below $0,5 \mathrm{~mm}$. The camera tripods were placed at two different locations in front of the clay panel. The exterior orientations of the different photographs of the panoramas were processed in a photogrammetric bundle and imported in the point cloud processing software in order to get a very accurate coloured point cloud and meshed model. The same area is scanned at several times and different angles to overcome the problem of incidence of the laser in order to fill the holes of the model. The georeferencing of this very accurate point clouds is obtained after registration with the global $3 \mathrm{D}$ model of the cave. The use of this generation of scanner is undoubtedly a methodological advance.

Finally, we decided the same year to get down for the first time in an archaeological cave the latest generation of a Faro ScanArm V3 (19 200 points $/ \mathrm{sec}$ and 0,035mm accuracy). The exceptional quality of the acquisition of this point cloud is due to the accuracy of the FARO fusion arm and the laser V3 head maintained by the operator at a few centimetres of the object during the time consuming recording (Fig. 6). This new equipment, providing sub-millimetre resolution, has enabled the team to carry out experimental work on identifying the various techniques used and tools used to achieve the decorated panels. 
The study is conducted on several panels of the cavity and their experimental duplicates (made of clay materials using a wide range of tools: flint, bone, bronze and copper spikes, dry wood, freshly cut branches, fingertips, etc.). The objective is to discriminate different techniques as fingering, engraving, or etching from the traceology. The flexibility of the ScanArm was able to record the bottom of the prints and the finest carvings, including oblique ones. We want to compare archaeological models and experimental duplicates to compare sections drawn in order to discriminate the morphology or the type of tools used

\section{4. Discussion}

In the specific context of archaeological heritage caves, 3Drecording using contact-free measurement techniques is henceforth considered like the best way to acquire georeferenced information, without handling material nor damaging the site. There is no more any technical difficulty for the overall 3D recording of the structural elements of the cave. Several possibilities emerge, but we it is obvious that the latest generation of compact terrestrial laser scanners, including integrated camera, allow an optimized global 3D-digital terrain model, conceived as a common research tool, incorporating various type of georeferenced object, image or measurement. Since 2008, diverse challenges have been faced by the team, including the processing of very high definition images (and their mapping on the 3D-model) in order to obtain a photorealistic rendering, by combining photogrammetry and TLS. Our results show that it is not only possible to produce high resolution textured 3D-models, but also to develop new traceological approaches or to yield an alternative to the manual drawing technique of parietal art specialists by extracting orthophotos from the 3D-model.

The issue of the integration of heterogeneous data, acquired at different scales and resolutions, in a global 3D-model, has been too poorly investigated. This is still among the things we must do. Firsts results obtained show that we are able to merge together in the same depiction system, several roots of information (for instance for the magnetic field mapping).

\section{CONCLUSION}

At this stage, it is worthwhile to recognize that, despite of the accurate solutions found to repulse several methodological locks allowing the accuracy of 3D-recording while preserving the site, we are still looking forwards solutions to optimized the integration of heterogeneous data acquired at different scales and resolutions in a common depiction system. This requirement is clearly related to our interdisciplinary framework which occurs an integrated research. The work in progress as for magnetic field mapping establishes a very important methodological progress. But the exploitation of data is hampered by the necessity to expand mathematical developments and data processing tools (specific work-platform dedicated to the exploration of $3 \mathrm{D}$ data). In the short term, it is important to finish the entire 3D-recording of the whole cave and to find a way to put an end on the issue of merging several roots of information in the same depiction system. Afterwards, our goal will be using the global 3D-model of the cave to develop modelling approaches (history of karst, fireplaces operating modelling...).

\section{REFERENCES}

Burens et al. 2011 - Burens, A., Grussenmeyer, P., Guillemin, S., Carozza, L., Bourrillon, R., Petrognani, S.
2011.Numérisation 3 D de la grotte ornée des Fraux - SaintMartin-de-Fressengeas, Dordogne, France : Approche multiscalaire. Images et modèles 3D en milieux naturels, collection EDYTEM n¹2, 2011, pp. 183-189.

Carozza et al., 2009 - Carozza, L., Burens, A., Billaud,Y., Ferrulo, O., Bourrillon, R., Petrognani, S., Fritz, C., Tosello, G., Goineaud, E., Goineaud, M., 2009. L'horizontal et le vertical L'âge du Bronze de la grotte des Fraux (Saint-Martin-deFressengeas - Dordogne). In : De Méditerranée et d'ailleurs... Mélanges offerts à Jean Guilaine. Archives d'Ecologie Préhistorique Toulouse, 2009, pp. 159-172.

El-Hakim et al, 2004 - El-Hakim, S.F., Fryer, J.G., Picard, M., 2004. Modelling and visualization of aboriginal rock art in the Baiame cave. International Archives of Photogrammetry and Remote Sensing, 35, 5, pp. 990-995.

Fryer et al, 2005 - Fryer, J.G., Chandler, J.H., El-Hakim, S.F., 2005. Recording and modelling an aboriginal cave painting: with or without laser scanning. In: 1 st $3 \mathrm{D}-\mathrm{ARCH}$ International Symposium, Mestre-Venice, Italy. International Archives of Photogrammetry, Remote Sensing and Spatial Information Systems, XXXVI-5/W17, 8 p.

Gonzales-Aguilera et al, 2009 - Gonzales-Aguilera, D., Munoz-Nieto, A., Gomez-Lahoz, J., Herrero-Pascual, J., Guitirrez-Alonso, G. 3D Digital surveying and modelling of cave geometry: Application to Paleolithic Rock art. Sensors, 9, pp. 1108-1127.

Grussenmeyer et al, 2010a - Grussenmeyer, P., Cazalet, B., Burens, A., Carozza, L., 2010 a. Close range terrestrial laser scanning and photogrammetry for the $3 \mathrm{D}$ documentatin of the Bronze age cave " les Fraux » Périgord, France. Mining in European History, Special Conference of the SFB HiMAT, Innsbruck 2010, Innsbruck university press, pp. 411-421.

Grussenmeyer et al, 2010b - Grussenmeyer, P., Landes, T., Alby, E., Carozza, L., 2010 b. High Resolution 3D Recording and Modelling of the Bronze Age Cave "les Fraux" in Périgord (France). ISPRS Comm. V Symposium, Newcastle upon Tyne, June 22-24, UK. Int. Arch. of Photogrammetry and Remote Sensing and Spatial Information Sciences, XXXVIII, 5, pp. 262-267.

Lerma et al, 2009 - Lerma, J., Navarro, S., Cabrelles, M., Villaverde, V. 2009. Terrestrial laser scanning and close range photogrammetry for 3D archaeological documentation: the Upper Palaeolithic Cave of Parpall — as a case study, Journal of Archaeological Science, 37, 3, pp. 499-507.

Lévêque et al 2010 - Lévêque, F., Mathé V., Brodard A., Guibert P, Carozza L., Burens A, Grussenmeyer P., Guillemin S. 2010. See the hearths in the prehistorical caves: 3D magnetic field mapping. 12th Castle Meeting on New trend in geomagnetism, Paleo, Rock and Environmental Magnetism, August 29 -September 10, 2010, Castle of Nové Hrady, Czech Republic. Travaux géophysique XXXIX, pp. 45.

\section{Acknowledgements:}

The study of Les Fraux takes place in a planned multi-year archaeological excavation funded by the regional office of Aquitaine of the French Ministry of Culture and Communication. The French National Research Council is also supporting this project labeled as a research site in Global Ecology (called SEEG). We would like to thank the FARO Company for its scientific partnership in this project. Thanks also to E. Moisan, V. Léglise and B. Cazalet for their contribution as a part of their training at INSA. With our warmest thanks to Edmond $(\dagger)$ and Marcelle Goineaud, owners of the cave « Les Fraux » who allowed us to publish the images produced in the cave. 